\title{
Preparation and Characterization of Poly(Ether Ether Ketone) Derivatives
}

\author{
Thiago F. Conceição, ${ }^{a}$ José R. Bertolino, ${ }^{a}$ Guilherme M. O. Barra,${ }^{b}$ Sandro L. Mireski, ${ }^{a}$ \\ Antônio C. Joussef ${ }^{a}$ and Alfredo T. N. Pires $*, a$ \\ ${ }^{a}$ Departamento de Química and ${ }^{b}$ Departamento de Engenharia Mecânica,
} Universidade Federal de Santa Catarina, Florianópolis-SC, Brazil

\begin{abstract}
Neste trabalho, três derivados do poli(éter éter cetona) [PEEK] foram preparados em suspensão por meio da nitração, redução para o grupo amino e redução da carbonila. Os polímeros modificados foram caracterizados por espectroscopia de infravermelho (FTIR), Ressonância Magnética Nuclear (NMR), análise termogravimétrica (TGA) e apresentaram características interessantes para a preparação de membranas e compósitos, tais como, basicidade e solubilidade em solventes orgânicos, como DMF.

In this study, three derivatives of poly(ether ether ketone) [PEEK] were prepared in suspension by nitration ( $\mathrm{NO}_{2}$-PEEK), reduction to the amino group ( $\mathrm{NH}_{2}$-PEEK) and carbonyl reduction (PEEK-OH). These modified polymers were characterized by NMR, IR spectroscopy and thermogravimetric analysis. They showed interesting characteristics, such as, basicity and higher solubility in organic solvents, like DMF, for use as membranes and composites in different applications.
\end{abstract}

Keywords: PEEK, polymer functionalization, NMR, IR spectroscopy

\section{Introduction}

The preparation of polymer derivatives is a very important research field, especially in materials science, due to the necessity for materials with specific properties. The poly(aryl ether ketone) type polymers are a class of high performance engineering thermoplastics which has a variety of applications, such as in aircraft and automobile industries. ${ }^{1}$ The most widely used material of this class is poly(ether ether ketone) [PEEK] which has very good thermal, mechanical and chemical stability. One of the drawbacks of PEEK is its insolubility in common organic solvents, which inhibits its chemical modification.

In the literature, two general methods to prepare PEEK derivatives are reported. Most modified PEEK samples are prepared by polymerization of previously functionalized monomers, a method that involves a great number of steps and can result in undesirable products due to competition reactions. ${ }^{2-4}$ The other common method of PEEK modification is to dissolve the polymer in strong acids, such as sulfuric acid, and add the second reactant, but this dissolu-

\footnotetext{
*e-mail: pires@qmc.ufsc.br
}

tion is usually followed by sulfonation and in some cases results in degradation of the polymer, which limits this method to a sulfonation reaction.,

However, some PEEK derivatives can be easily prepared in a single step reaction in suspension, without any competition reactions. The aim of this study is to prepare and characterize PEEK derivatives in suspension resulting in materials with distinct properties with applications in composites and membrane science.

\section{Experimental}

\section{Materials}

Poly(ether ether ketone) or poly(oxy-1,4-phenyleneoxy1,4-phenylenecarbonyl-1,4-phenylene) [PEEK 450P] was supplied by Victrex. N,N-dimethylformamide [DMF], dimethylsulfoxide [DMSO], sulfuric acid ( $98 \%$ grade), nitric acid $\left(65 \%\right.$ grade) and ferric chloride $\left[\mathrm{FeCl}_{3} \cdot 6 \mathrm{H}_{2} \mathrm{O}\right]$ were purchased from Nuclear. Sodium borohydride $\left[\mathrm{NaBH}_{4}\right]$ and palladium on activated charcoal ( $10 \%$ as $\mathrm{Pd})$ were purchased from Sigma-Aldrich and Fluka, respectively. All the reagents were used without further purification. 


\section{Preparation of $\mathrm{NO}_{2}-\mathrm{PEEK}$}

A stirred suspension of $4 \mathrm{~g}$ of PEEK in $50 \mathrm{~mL}$ of $\mathrm{HNO}_{3} / \mathrm{H}_{2} \mathrm{SO}_{4}(4: 1 \mathrm{v} / \mathrm{v})$ was heated under the conditions specified in Table 1 . The product $\left(\mathrm{NO}_{2}\right.$-PEEK) was filtered and washed with water until $\mathrm{pH} 7$, ethanol $(2 \times 50 \mathrm{~mL})$, acetone $(2 \times 100 \mathrm{~mL})$ and dried in an oven at $80{ }^{\circ} \mathrm{C}$. The yellow solid was dissolved in DMF $(60 \mathrm{~mL})$, filtered and precipitated by addition of $\mathrm{HCl}\left(10 \mathrm{~mL}, 1 \mathrm{~mol} \mathrm{~L}^{-1}\right)$. The precipitated was filtered, washed with water, ethanol and dried in an oven at $80{ }^{\circ} \mathrm{C}$. To evaluate the effect of $\mathrm{FeCl}_{3}$, $1 \mathrm{~g}$ of this salt was added in batches 1, 6 and 8 .

Table 1. Conditions of the nitration reaction and the nitration degree of the products

\begin{tabular}{ccccc}
\hline Batch & $\mathrm{T} /\left({ }^{\circ} \mathrm{C}\right)$ & $\begin{array}{c}\text { Reaction } \\
\text { time } / \\
(\mathrm{min})\end{array}$ & $\mathrm{FeCl}_{3}{ }^{\mathrm{a}}$ & $\begin{array}{c}\text { Nitration } \\
\text { Degree }^{\mathrm{b}} \\
(\%)\end{array}$ \\
\hline 1 & 25 & 30 & $\mathrm{X}$ & 8 \\
2 & 25 & 60 & & 6 \\
3 & 50 & 30 & & 69 \\
4 & 50 & 60 & & 71 \\
5 & 65 & 30 & & 83 \\
6 & 65 & 30 & $\mathrm{X}$ & 93 \\
7 & 65 & 60 & & 93 \\
8 & 65 & 60 & $\mathrm{X}$ & 113 \\
9 & 75 & 90 & & 247 \\
\hline
\end{tabular}

a " $\mathrm{X}$ " indicates the presence of this salt; ${ }^{\mathrm{b}}$ The nitration degree (ND) was estimated by TG curves

\section{Preparation of $\mathrm{NH}_{2}-\mathrm{PEEK}$}

A suspension of $\mathrm{NO}_{2}$-PEEK, from batches 3 and 5 (see Table 1$)$, and $10 \% \mathrm{Pd} / \mathrm{C}(0.40 \mathrm{~g})$ in DMF $(30 \mathrm{~mL})$ was hydrogenated in a Parr Hydrogenator Apparatus for $24 \mathrm{~h}$. After, the reaction mixture was filtered on a bed of celite to remove the catalyst and $\mathrm{HCl}\left(10 \mathrm{~mL}, 1 \mathrm{~mol} \mathrm{~L}^{-1}\right)$ was added to the filtrate to precipitate the product. The solid was collected by filtration, washed with water and dried in an oven at $80^{\circ} \mathrm{C}$.

\section{Preparation of PEEK-OH}

PEEK ( $4 \mathrm{~g})$ was added portion wise $(c a .5 \mathrm{~min})$ in a stirred solution of $\mathrm{NaBH}_{4}(1.2 \mathrm{~g})$ in DMSO $(100 \mathrm{~mL})$ and the suspension was heated at $120{ }^{\circ} \mathrm{C}$ for $3 \mathrm{~h}$. After cooling at room temperature, the suspension was filtered and the solid was washed with ethanol $(2 \times 30 \mathrm{~mL})$, methanol $(2 \times 15 \mathrm{~mL})$, water $(2 \times 30 \mathrm{~mL}), \mathrm{HCl}\left(2 \times 10 \mathrm{~mL}, 1 \mathrm{~mol} \mathrm{~L}^{-1}\right)$ and dried in an oven at $80^{\circ} \mathrm{C}$.

\section{Infrared (FTIR)}

FTIR analysis was performed on a Bomem spectrometer, model FTL 2000, performing 20 scans at a resolution of 4 $\mathrm{cm}^{-1}$, on $\mathrm{KBr}$ pellets. All samples were dried and purified before analysis.

Nuclear magnetic resonance (NMR)

Nuclear magnetic resonance was recorded on the Varian AS-400 spectrometer. The nitrated PEEK was dissolved in DMSO- $\mathrm{d}_{6}, \mathrm{ca} .3 \%$ solution, for ${ }^{13} \mathrm{C}$ NMR analysis. PEEK$\mathrm{OH}$ and PEEK were analyzed by solid state NMR.

Thermogravimetric analysis (TGA)

Thermal stability analysis of the polymers was carried out on a TGA-50 (Shimadzu, Japan) under nitrogen atmosphere $\left(50 \mathrm{~cm}^{3} \mathrm{~min}^{-1}\right)$ using an average sample of $7 \mathrm{mg}$. The nitration degree (ND) of $\mathrm{NO}_{2}$-PEEK was calculated by the TG curves. Non-isothermal experiments were performed in the temperature range of $25-650{ }^{\circ} \mathrm{C}$ at a heating rate of $10{ }^{\circ} \mathrm{C} \min ^{-1}$ for each sample.

\section{Results and Discussion}

Preparation of $\mathrm{NO}_{2}-\mathrm{PEEK}$

Poly(ether ether ketone) [PEEK] is a high-performance engineering thermoplastic with excellent mechanical and thermal stability, which can undergo chemical modifications by attachment of functional groups to its aromatic rings, and by reactions in its carbonyl group. ${ }^{7}$ The nitration of PEEK is an electrophilic substitution reaction where the nitro group is introduced preferentially in the hydroquinone segment of the polymer chain, as shown in Figure 1a, due to the activation effect of the ether linkage. The nitration of the benzophenone segment can be accomplished after the nitration of the hydroquinone ring, as shown in Figures $1 \mathrm{~b}$ and $1 \mathrm{c}$, which is deactivated by the nitro group.

There are few studies on PEEK nitration reported in the literature. Karcha et al. performed the nitration of PEEK to different degrees, by dissolution in methane sulfonic acid and addition of nitric acid. ${ }^{8}$ Cui and Kerres described the nitration of PEEK and other aryl polymers by PEEK dissolution in concentrated sulfuric acid, followed by gradual addition of nitric acid. ${ }^{9,10}$ The method used in this study is easier and cleaner than these methods described in the literature, since the reaction occurs without dissolution of the polymer. Table 1 shows the nitration degree for different reaction times and temperatures, and in the presence 

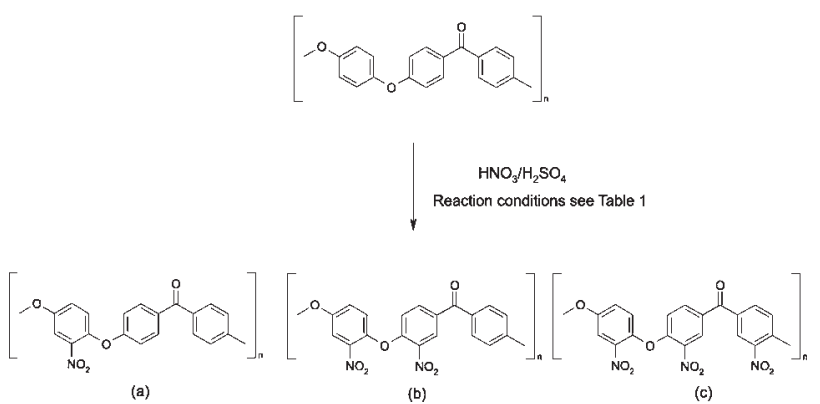

Figure 1. Representative scheme of PEEK at different nitration degree (ND), (a) $\mathrm{NO}_{2}$-PEEK ND < 100, (b) $\mathrm{NO}_{2}$-PEEK $100<\mathrm{ND}<200$, (c) $\mathrm{NO}_{2}$-PEEK $\mathrm{ND}<300$.

and absence of $\mathrm{FeCl}_{3}$. As can be seen for batches 5-6 and $7-8$, the presence of this salt increased the nitration degree by around $10 \%$. $\mathrm{NO}_{2}$-PEEK is a yellow compound which at nitration degrees higher than $60 \%$ becomes soluble in solvents such as DMF, DMAC, THF, DMSO and $\mathrm{CCl}_{3} \mathrm{H}$, at room temperature.

Figure 2 shows the infrared spectra for PEEK and nitrated PEEK in different nitration degrees, and the absorption bands observed at $1532 \mathrm{~cm}^{-1}$ and $1348 \mathrm{~cm}^{-1}$ relate to the unsymmetrical and symmetrical stretching of the nitro group, respectively. The absorption band at $1260 \mathrm{~cm}^{-1}$ and the shoulder at $1188 \mathrm{~cm}^{-1}$ correspond to $\mathrm{C}-\mathrm{N}$ stretching and to the angular deformation of the $\mathrm{C}-\mathrm{H}$ bond of the three-substituted ring, respectively. In the spectra of $\mathrm{NO}_{2}$-PEEK $247 \%$ (nitration degrees higher than 100 indicates more than one nitro group per monomer) an absorption band appears at $1722 \mathrm{~cm}^{-1}$ due to another carbonyl stretching, suggesting the nitration of an aromatic ring of the benzophenone segment. The appearance of an absorption band at $1075 \mathrm{~cm}^{-1}$ related to another C-H angular deformation also suggests the occurrence of this nitration.

The NMR spectrum of the $\mathrm{NO}_{2}$-PEEK, with ND of $69 \%$, given in Figure 3, shows two peaks between

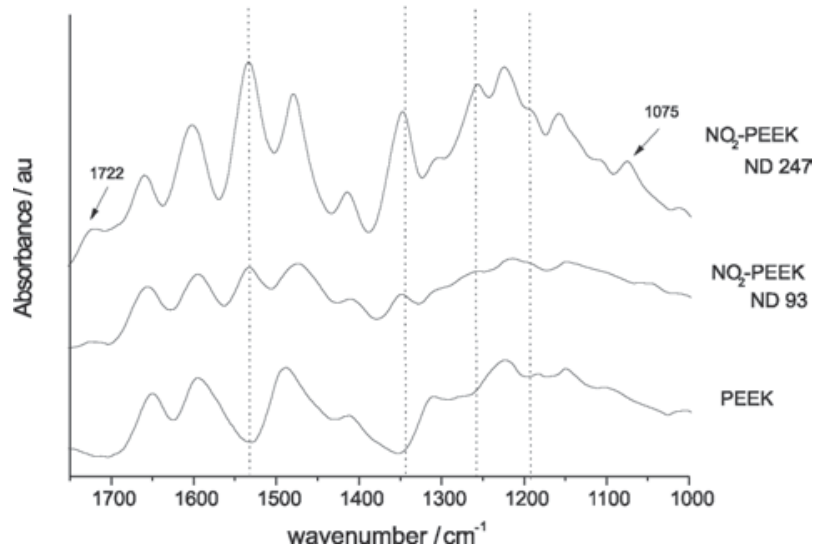

Figure 2. FTIR spectra of PEEK and nitrated PEEK in two different nitration degrees.
$140-150 \mathrm{ppm}$, at $142.8 \mathrm{ppm}$ and $144.8 \mathrm{ppm}$, related to the carbons 9' and 8' of the nitrated ring, respectively. The presence of only one carbonyl peak at $194 \mathrm{ppm}$ indicates that at ND values lower than $100 \%$ the nitration occurred only in the hydroquinone segment of the macromolecule. This result is consistent with Xing et al. who performed the sulfonation of PEEK, also an electrophilic substitution reaction and observed that for sulfonation degrees lower than $100 \%$ the addition of the sulfonic group occurred only in the hydroquinone segment. ${ }^{11}$ On the other hand, in the NMR spectrum of the $247 \% \mathrm{NO}_{2}$-PEEK appeared three carbonyl peaks, at $193.8 \mathrm{ppm}, 192.1 \mathrm{ppm}$, $190.1 \mathrm{ppm}$ and the peaks related to the carbons 5 and 14 appeared at $167.3 \mathrm{ppm}$ and $165.7 \mathrm{ppm}$, which indicated that the nitration of the benzophenone segment was in agreement with infrared data.

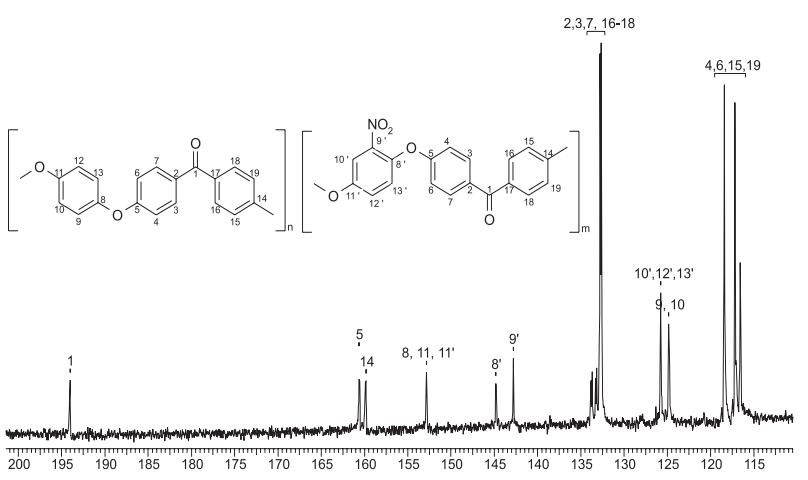

Figure 3. NMR of nitrated PEEK, ND 69.

The thermogravimetric curves are showed in Figure 4. $\mathrm{NO}_{2}$-PEEK is thermally stable up to $350{ }^{\circ} \mathrm{C}$ and exhibits two distinct weight loss stages, in contrast to PEEK, which has only one weight loss at $550{ }^{\circ} \mathrm{C}$. The nitration degrees (ND) shown in Table 1 were calculated rby the first weight loss stage, which is related to the decomposition of nitro groups. The result of this calculation was compared with the elemental analysis data. For the $\mathrm{NO}_{2}$-PEEK with the reaction conditions of $1 \mathrm{~h}$ and $65^{\circ} \mathrm{C}$, the elemental analysis gave an ND of $88 \%$ and the value obtained from the TG curve was of $93 \%$. This result is in agreement with Xing et al., who showed that the sulfonation degree of SPEEK could be estimated by the TG curves, with a difference of about $5 \%$ compared to the value obtained by other methods.

The product of the reaction in which $\mathrm{FeCl}_{3}$ was used shows another weight loss stage below $200{ }^{\circ} \mathrm{C}$. This is probably related to water and to $\mathrm{FeCl}_{3}$ decomposition, which indicates that this compound can remain in the product as an impurity even after purification. A high nitration degree without contamination can be achieved with high temperatures and long reaction times, as can be seen in the curve of $\mathrm{NO}_{2}$-PEEK ND 247. 


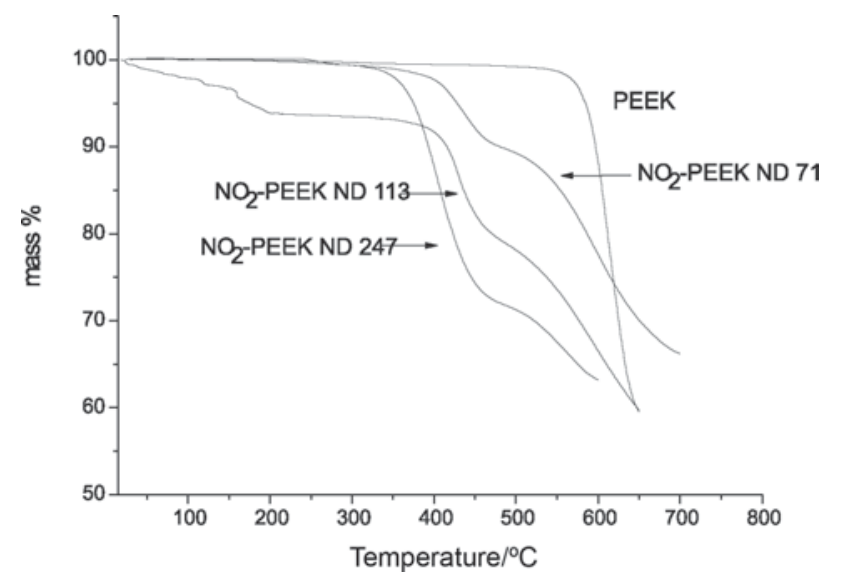

Figure 4. TGA of the nitrated compounds. ND indicates the nitration degree.

\section{Preparation of $\mathrm{NH}_{2}-\mathrm{PEEK}$}

The reduction of the nitro aromatic group to its respective amine can be accomplished by different methods. Dowing et $a l .{ }^{12}$ described the catalytic hydrogenation of aromatic nitro compounds with various catalysts. Banik et al. ${ }^{13}$ presented a method using samarium and iodine as the reduction agents. Ratio et al. used a mixture of iron powder, acetic acid, ethanol and water to reduce the nitro group without affecting the carbonyl, and a series of studies present nitro reduction methods using hydrazine. ${ }^{14-17}$ The catalytic hydrogenation method was used in this study because it is the cleanest and simplest. With the right choice of catalyst there is no competition reaction and the product is easily recovered by filtration. The reaction scheme is shown in Figure 5.

As with $\mathrm{NO}_{2}$-PEEK, studies on aminated PEEK are sparsely reported in the literature. Cui and Kerees performed the amination of PEEK by dissolution of the nitro compound in DMF with further addition of a solution of $\mathrm{Na}_{2} \mathrm{~S}_{2} \mathrm{O}_{4}$ in water and $\mathrm{HCl} \cdot{ }^{7-8}$ Another study with amination on the carbonyl group is given in reference. ${ }^{18}$

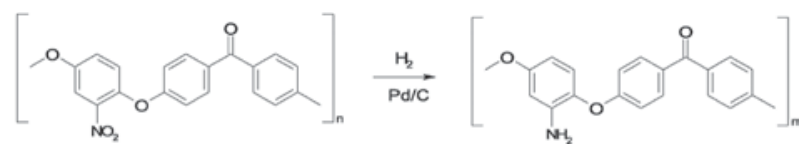

Figure 5. Scheme of the $\mathrm{NO}_{2}$-PEEK reduction.

Figure 6 shows the FTIR spectra of PEEK, $\mathrm{NO}_{2}$-PEEK and $\mathrm{NH}_{2} \mathrm{PEEK}$ where the disappearance of the bands at $1532 \mathrm{~cm}^{-1}$ and $1348 \mathrm{~cm}^{-1}$, related to the nitro group, can be seen, along with the appearance of a weak band at $3365 \mathrm{~cm}^{-1}$, related to the N-H stretching. The total disappearance of the absorption bands related to the nitro group indicate that all the nitro groups were reduced to amino groups, and the amination degree (AD) is equal to the nitration degree of $\mathrm{NO}_{2}$-PEEK. The absorption bands at $3500 \mathrm{~cm}^{-1}$, present in the three spectra, are related to end functions.

The $\mathrm{NH}_{2}$-PEEK is a brown compound which is soluble in DMF, DMAc and DMSO. The amino group in the hydroquinone segment gives the compound a highly basic nature, making it suitable for further modification. This highly basic characteristic makes it less stable than the nitro compound, as shown in Figure 7. The degradation of the main chain of $\mathrm{NH}_{2}$-PEEK occurred at temperatures lower than those for PEEK and $\mathrm{NO}_{2}$-PEEK, which may be related to reactions with the main chain and derivatives of the amino group.

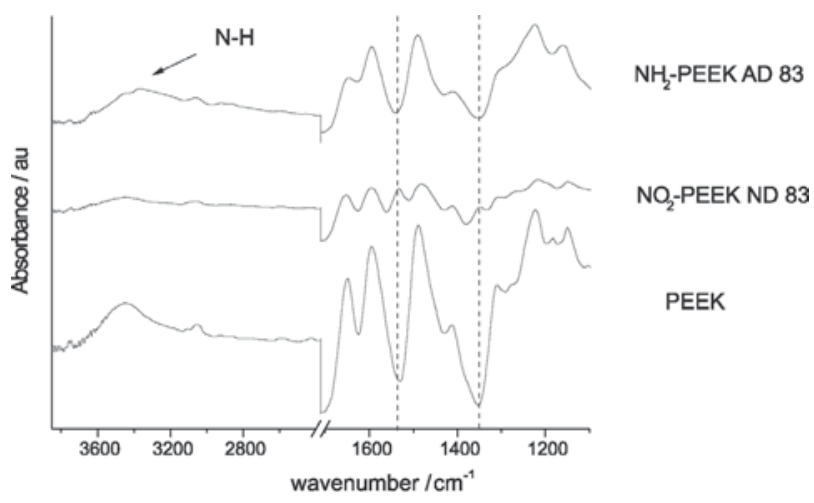

Figure 6. FTIR spectra of PEEK, $\mathrm{NO}_{2}$-PEEK and $\mathrm{NH}_{2}$-PEEK.

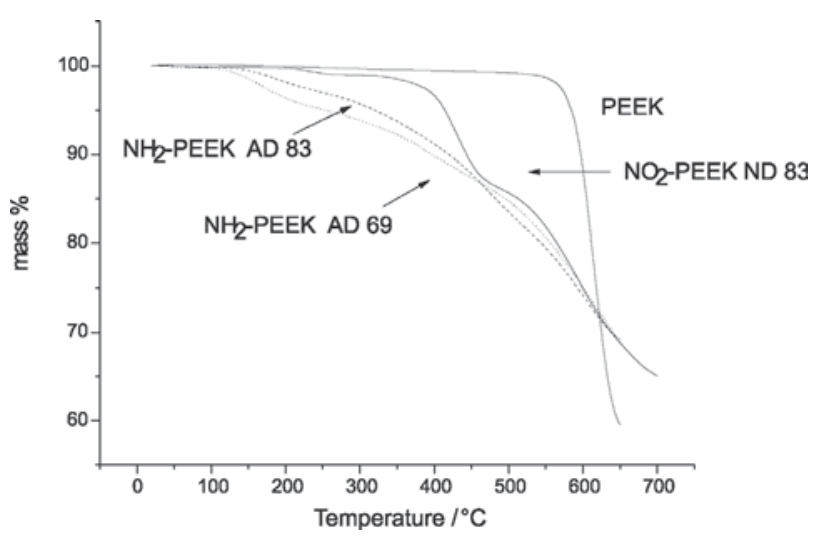

Figure 7. TG curves for the $\mathrm{NH}_{2}$-PEEK, $\mathrm{NO}_{2}$-PEEK and PEEK. In the $\mathrm{NH}_{2}$-PEEK, AD indicates the degree of amino groups.

\section{Preparation of PEEK-OH}

The conversion of ketone to alcohol was carried out using $\mathrm{NaBH}_{4}$, as is shown in Figure 8. PEEK and PEEK-OH are not soluble in DMSO and thus the recovery of the product is a very simple procedure. The literature reports the reduction of the PEEK film surface, for example, the studies of Henneuse-Boxus et al. and Marchand-Brynaert et al. who performed a series of surface modifications to 
PEEK by the reduction of the carbonyl group. ${ }^{19-20}$ There is a lack of studies on the bulk reduction of PEEK as here reported here. The ${ }^{13} \mathrm{C}$ NMR of solid samples, shown in Figure 9, show the presence of a peak at $62.55 \mathrm{ppm}$, related to the carbon linked to the hydroxyl group and a diminishing of the peak at $192 \mathrm{ppm}$, corresponding to the carbon of the carbonyl group. The FTIR spectrum for this compound corroborated the reduction success, showing the accentuation of the absorption band at $3400 \mathrm{~cm}^{-1}$ referent to water or end functions in PEEK and to the O-H stretching in PEEK-OH.

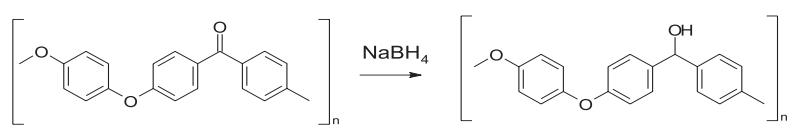

Figure 8. Reduction scheme.

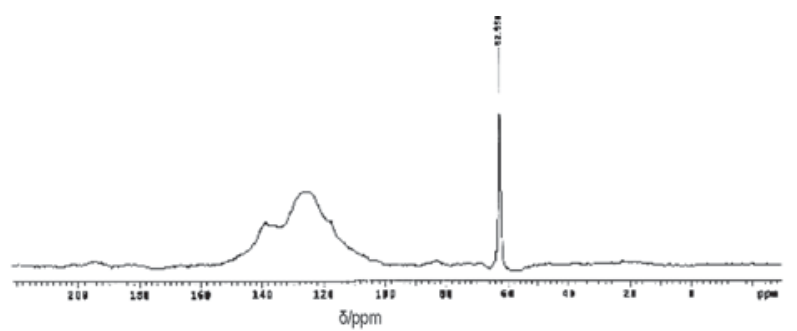

(a)

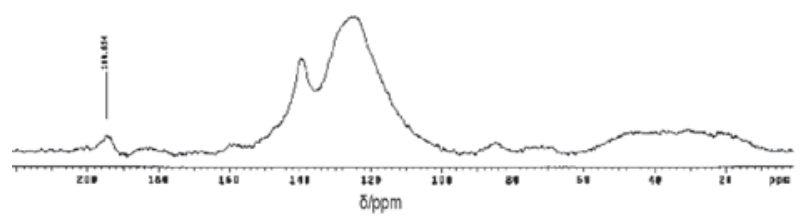

(b)

Figure 9. (a) ${ }^{13} \mathrm{C}$ NMR spectra of solid samples of PEEK-OH (b) ${ }^{13} \mathrm{C}$ MR spectra of solid PEEK samples.

The reduction did not produce significant changes in the physical aspect of the compound and no solubility changes were observed. Figure 10 shows the TG results for PEEK-OH. The degradation of the reduced compound began at a temperature lower than that for PEEK. In PEEK, all the carbons are $\mathrm{sp}^{2}$, which is favorable for a good packing of the molecules, whereas, in PEEK-OH, the presence of $\mathrm{sp}^{3}$ carbons inhibits the molecular packing. Also, the resonance effect is less pronounced in PEEK-OH than in PEEK, which leads to a lower thermal stability.

\section{Conclusions}

The nitration of PEEK results in a yellow compound, soluble in organic solvents, such as DMF, and thermally

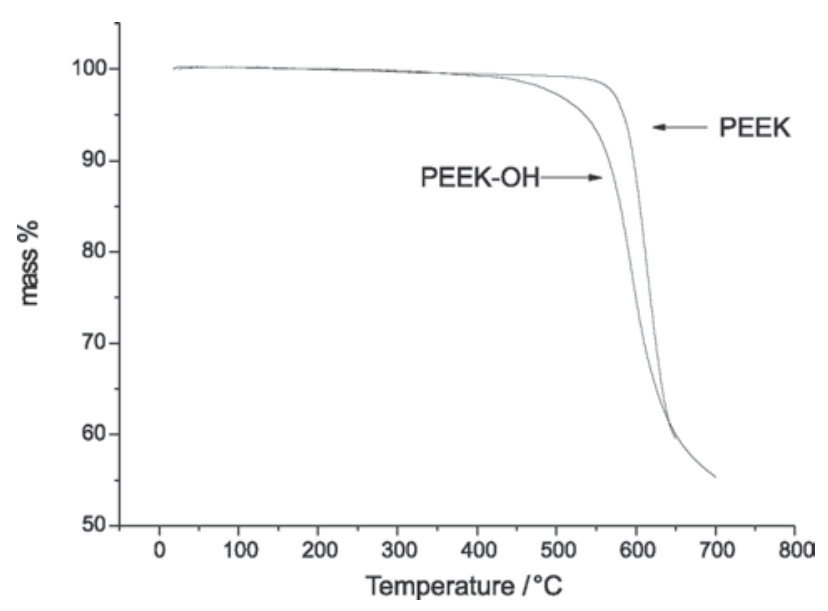

Figure 10. TG curves for PEEK and PEEK-OH.

stable up to $350{ }^{\circ} \mathrm{C}$. For nitration degrees lower than $100 \%$ the nitration takes place only in the hydroquinone segment of the polymer main chain, but for nitration degrees higher than $100 \%$ the nitration occurred in the benzophenone segment. The reduction of $\mathrm{NO}_{2}$-PEEK can be easily achieved by catalytic hydrogenation without any competition reaction, resulting in $\mathrm{NH}_{2}$-PEEK, a brown compound also soluble in DMF. $\mathrm{NH}_{2}$-PEEK is thermally stable up to $100{ }^{\circ} \mathrm{C}$ and has a basic nature, which makes it suitable to undergo further modifications, resulting others derivatives of PEEK. The reduction of the carbonyl to the hydroxyl group produces a small loss in the thermal stability of the compound, due to a decrease in the resonance effect and the spatial organization. No solubility changes were observed. All three synthesized compounds can undergo further modifications, resulting in new PEEK derivatives.

\section{References}

1. Guen, A. Le; Klapper, M.; Müllen, K.; Macromolecules 1998, $31,6559$.

2. Wang, F.; Roovers, J.; Macromolecules 1993, 25, 5295.

3. Gao, X; Wang, R.; Zhang, A.; Mater. Lett. 2007, 61, 3647.

4. Hergenrother, P. M.; Jensen,, B. J.; Havens, S. J.; Polymer 1988, $29,358$.

5. Bishop, M. T.; F. E.; Russo, P. S., Langley, K. H.; Macromolecules 1985, $18,86$.

6. Zaidi, S. M. J. ; Mikhailenko, S. D.; Robertson, G. P.; Guiver, M. D.; Kaliaguine, S. ; J. Membr. Sci. 2000, 173, 17.

7. Rose, J. B. In High Performance Polymers: their Origin and Development; Seymour, R. B., Kirshenbaum, G. S.(eds.), Elsevier: New York, 1986, p 187.

8. Karcha, R. J.; Porter R. S; J. Macromol. Sci., Part A: Pure Appl. Chem. 1995, 32, 957.

9. Cui, W.; U.S. Patent 6878803, 2005.

10. Kerees, J.; U.S. Patent 6509441, 2003. 
11. Xing, P.; Robertson, P.; Guiver, M. D.; Mikhailenko, S. D.; Wang, K., Kaliaguine, S., J. Membr. Sci. 2004, 229, 95.

12. Dowing, R. S.; Kunkeler, P. J.; Bekkum, H. V.; Catal. Today 1997, 37, 121

13. Banik, K. B.; Mukhopadhyay, C.; Venkatraman, M. S.; Becker, F. F.; Tetrahedron Lett. 1998, 39, 7243.

14. Raitio, K. H.; Savinainen, J. R.; Vepsäläinen, J.; Laitinen, J. T.; Poso, A.; Järvinen, T.; Nevalainen T.; J. Med. Chem. 2006, 49, 2022.

15. Lauwiner, M.; Roth, R.; Rys, P.; Appl. Catal., A. 1999, 177, 9.

16. Lauwiner, M.; Rys, P.; Wissmann, J.; Appl. Catal., A. 1998, 172,141 .
17. Benz, M.; Prins, R.; Appl. Catal., A. 1999, 183, 325.

18. Henneuse-Boxus, C.; Boxus, T.; Duliere, E.; Pringalle, C.; Tesolin, L.; Adriaensen, Y.; Marchand-Brynaert, J.; Polymer 1998, 39, 5359 .

19. Henneuse-Boxus, C.; Boxus, T.; Dulière, E.; Pringalle, C.; Tesolin, L.; Adriaensen, Y.; Marchand-Brynaert, J.; Polymer 1998, 39, 5359 .

20. Henneuse, C.; Goret, B.; Marchand-Brynaert, J.; Polymer 1998, 39,835 .

Received: June 4, 2007 Published on the web: January 28, 2008 